\title{
Corneal complication caused by gonococcal conjunctivitis
}

\author{
Complicação corneana por conjuntivite gonocócica
}

\author{
Thiago Gonçalves dos Santos Martins ${ }^{1}$, Grace Peng ${ }^{1}$, Roberta Andrade e Nascimento ${ }^{1}$, \\ Ana Luiza Fontes de Azevedo Costa ${ }^{2}$
}

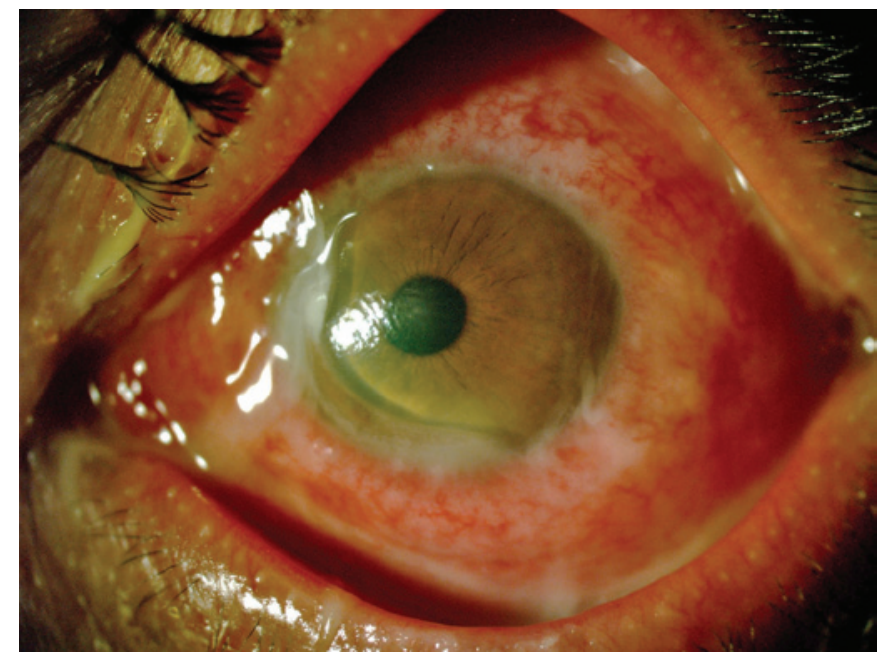

Figure 1. Significant corneal thinning

A 39-year-old man, MAFS, was admitted to ophthalmology emergency service of the Universidade Federal de São Paulo reporting low vision and ocular hyperemia with purulent discharge for 12 days in the left eye, but without complaints in the right eye. The patient administered ciprofloxacin drop every 3 hours. Upon examination, he had diffuse ocular hyperemia, chemosis, and extensive area of corneal thinning in nasal region, which had purulent discharge. The visual acuity in the affected eye was 20/80. Bacterioscopy revealed gram-negative diplococcic and the culture confirmed the presence of gonococcus. The patient was referred to the urologist for assessment of other sexual transmissible disease. After examination, he was diagnosed with HIV infection. The treatment comprised of azithromycin $1 \mathrm{~g}$ orally and ceftriaxone intravenously for 3 days. After, the patient was submitted to tectonic corneal transplantation to reestablish eye integrality that was threatened by thinning of the area, which probably would have had a perforation if the patient did not undergo the early transplantation.

Eye infection may occur with or without urogenital infection. In this report no infection was detected by the urologist. ${ }^{(1,2)}$ For eye infection, topic antibiotics reach the infected tissues in higher concentration than systemic treatment, however, in case of gonococcal eye infection the systemic treatment is also needed, which is prolonged for 3 days when cornea is affected. ${ }^{(3)}$

Gonococcal infection, as the cause of conjunctivitis, may generate several corneal complications such as the one presented in this case. Gonococcal conjunctivitis must be treated immediately by the ophthalmologist in order to preserve patient's vision and ocular integrity.

\section{REFERENCES}

1. Harry T, Black P. Unilateral gonococcal ophthalmia without genital infection: an unusual presentation in an adult. Int J STD AIDS. 2005;16(1):78-9.

2. Gambrelle J, Ponceau B, Duquesne N, Crepet H, Fleury J, Burillon C, et al. [Gonococcal conjunctivitis complicated by perforating corneal abscess in an adult]. J Fr Ophtalmol. 2007;30(7):e18. French.

3. Day AC, Ramkissoon YD, George S, Corbett MC. Don't forget Gonococcus! Eye (Lond.). 2006;20(12):1400-2. Review.

\footnotetext{
Universidade Federal de São Paulo, São Paulo, SP, Brazil.

${ }^{2}$ Hospital Federal dos Servidores do Estado, Rio de Janeiro, RJ, Brazil.
}

Corresponding author: Thiago Gonçalves dos Santos Martins - Universidade Federal de São Paulo, Rua Botucatu, 821, 2nd floor - Vila Clementino - Zip code:04023-062 - São Paulo, SP, Brazil Phone: (55 11) 5085-2010 - E-mail: thiagogsmartins@yahoo.com.br

Received on: Nov 15, 2013 - Accepted on: Apr 3, 2014

DOI: 10.1590/S1679-45082015Al3024 